\title{
BIOETHICS
}

RESEARCH LIBRARY

at GEORGETOWN UNIVERSITY

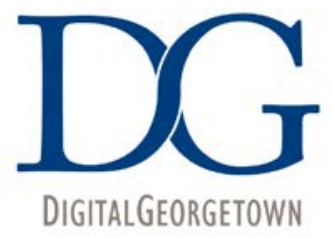

Bioethics Research Library at Georgetown University

https://repository.library.georgetown.edu/handle/10822/503786

The author made this article openly available online at the

Georgetown University Institutional Repository.

The Bioethics Research Library is collaborating with Georgetown's University Library to digitize, preserve and extend the history of Bioethics.

Please tell us how this access affects you. Your story matters.

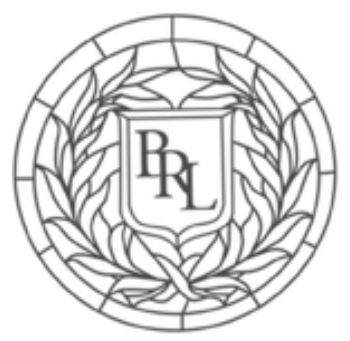

Visit us at https://bioethics.georgetown.edu/.

Copyright (C) 1993 The Johns Hopkins University Press. This article first appeared in Kennedy Institute of Ethics Journal, Volume 3 Issue 1; March 1993 pages 1-19.

Collection Permanent Link: hdl.handle.net/10822/503786

This material is made available online with the permission of the author, and in accordance with publisher policies. No further reproduction or distribution of this copy is permitted by electronic transmission or any other means. 


\section{Forgoing Life-Sustaining Treatment: Limits to the Consensus}

This is the second of a two-part series. In the December 1992 issue, Alan Meisel discussed the legal consensus about forgoing life-sustaining treatment.

ABSTRACT. While substantial progress has been made in reaching a moral and policy consensus regarding forgoing life-sustaining treatment, several holes exist in that consensus where more public discussion and moral analysis is needed. First, among patients who have not been found to be legally incompetent there is controversy over whether certain treatments can be refused. Controversies also remain over damages for treatment without consent, limits based on third-party interests and the ethical integrity of the medical profession, and cases where it cannot be agreed whether the patient is competent. Even greater dispute exists over care of incompetent patients. Perhaps the greatest gap in the consensus arises over limits to the use of the best interests standard. This article proposes replacing it with a "reasonableness standard" that takes into account disputes about what is literally the best for the patient and conflicts of interest between the patient and others.

$\mathrm{I}$

N THE PREVIOUS ISSUE of this journal, Alan Meisel (1992) provides a definitive statement of the legal consensus that has emerged from the past 20 years of moral and legal controversy over forgoing lifesustaining treatment in the United States. He carefully summarizes the evolution of the law and identifies a short list of points that characterize the legal consensus.

At the same time, as Meisel indicates, there are limits to this consensus. First, not every decision to forgo treatment that is accepted as legal is necessarily ethical. Many who are willing to tolerate the legality of, for 
example, a refusal of a blood transfusion by a competent adult would nevertheless consider such refusals morally unacceptable, especially when they have significant emotional and economic effects on other parties such as friends and relatives. Second, on some morally and legally controversial issues no consensus has emerged. Active killing for mercy and the right of a patient to care deemed futile by the attending clinician are two examples Meisel cites.

However other limits to the consensus get much less attention. They involve cases that do not fit fully within the categories envisioned in the consensus, and when they arise they tend to leave the parties involved morally and legally perplexed. It is worth identifying these cases so that we can begin to resolve in advance the problems they raise. Often they are cases of theoretical importance because they force us to define precisely the content of the consensus and the exact meaning of the principles it incorporates. Some of these cases involve patients who are competent or at least have not been legally determined to be incompetent. Others, often the more difficult ones, involve legally incompetent patients.

\section{PATIENTS WHO ARE NOT LEGALLY INCOMPETENT}

Many commentators on the ethics and law of treatment refusal distinguish between competent and incompetent patients only to make the point that for cases involving competent patients the policy issues are pretty well settled. The moral principle of autonomy or the related legal notions of liberty, privacy, and self-determination are seen as dominating the policy discussion even though the legal right of refusal and the moral right to act autonomously do not necessarily establish that refusing treatment is the right thing to do. In fact, however, some issues involving patients who are not legally incompetent leave us perplexed morally and legally and press us to the limits of the consensus. Before discussing the problems related to incompetent patients, we should note these areas where we lack agreement about dealing with patients.

\section{Refusals Not Covered By Statute}

The early refusals of treatment involved ventilators, dialysis machines, and other high-tech medical equipment. Gradually, we have recognized that the moral logic that supports forgoing these treatments can also support forgoing simpler, more routine interventions. It is now wellaccepted that treatments are not morally required if they do not offer benefits that exceed the envisioned burdens, that is if they do not meet 
the test of proportionality. Nevertheless, a small number of refusals appear to conflict with state forgoing-treatment statutes, principally, those statutes pertaining to the terminally ill which permit refusal only when death is imminent. A significant number of statutes explicitly exclude refusal of medically supplied nutrition and hydration, and some exclude refusal of medications even though such treatment might meet the proportionality test.

Several court cases have tested the right of individuals to refuse these excluded interventions. Florida, Colorado, and Maryland, for example, have all seen legal opinions that authorize patients to refuse medically supplied nutrition (Corbett v. D’Alessandro, 487 So. 2d 368 (Fla. Dist. Ct. App.), review denied, 492 So. 2d 1331 (Fla. 1986); In re Browning, 568 So. 2d 4 (Fla. 1990); In re Rodas, No. 86PR139 (Colo. Dist. Ct. Mesa County Jan. 22, 1987)(Buss, J.); Md. Op. Att'y Gen. 73: 253-96 (Op. No. 88-046, Oct. 17, 1988)). These decisions have been grounded in state Constitutional and common law rights. They now may come under the U.S. Supreme Court's presumption in favor of refusal even of medicallysupplied nutrition and hydration.

Still other refusals on the horizon press beyond even this tentative expansion of the consensus, and are certain to generate a real test of the consensus.

Oral Nutrition and Hydration. The debate over the withholding of medically-supplied nutrition and hydration (NG tubes, gastrostomies, parenteral nutrition) has often focused on the question of whether such interventions are "medical" (Meilaender 1984; Lynn and Childress 1983). The working moral presumption seems to be that medical procedures may be forgone while non-medical ones may not. As Meisel (1992, p. 325) reports, the Cruzan court (Cruzan v. Harmon, 760 S.W. 2d 408 (Mo. 1988); Cruzan v. Director, 110 S. Ct. 2841 (1990)) and other recent sources have tended to accept that these are medical and may be forgone.

But the question is beginning to arise whether the classification of treatments as medical is morally relevant. The consensus seems to be that what makes an intervention expendable is its uselessness or that the burdens are disproportional to the benefits. As yet, we do not have agreement on whether this applies to medical procedures only. Oral feeding is normally assumed not to be medical. Even most who defend forgoing medicallysupplied feeding are reluctant to accept the refusal of oral feeding. Yet, does it make any sense to hold that useless and burdensome medical procedures may be forgone while useless and burdensome nonmedical 
ones may not? We can expect a new round of controversy over the ethics and law of a patient's demand to forgo oral feeding. The test case is likely to be a terminally ill, imminently dying patient who has refused medicallysupplied nutrition and is rendered so uncomfortable by oral feeding that it is refused as well. The feeding may itself be painful (as with a patient with throat cancer) or the feeding may simply keep the patient conscious and alert so that discomfort is greater. Is there any moral reason why the proportionality logic developed first for complex medical treatments and then applied to medically-supplied nutrition could not also be applied to oral feeding?

Operating Room CPR. Decisions by competent patients to decline cardio-pulmonary resuscitation are now routinely accepted as morally and legally appropriate in cases where CPR would merely prolong the agony of the dying patient. Some such patients, however, are nevertheless candidates for operating room procedures. The advanced cancer patient, for instance, may be appropriate for palliative surgery requiring anesthesia.

The consensus is once again pushed to its limits when a patient who has prepared a valid instruction refusing CPR happens to suffer a cardiac arrest in the operating room. Even physicians who generally accept the wisdom of non-resuscitation decisions are given pause when the arrest is physician induced. They are willing to accept that nothing should be done for a "natural" arrest, but are not as quick to accept one they have induced themselves.

The argument is, in part, technical. A non-resuscitation decision might be supported by the rationale that the patient's arrest would signal a collapse of bodily function. The pre-existing illness combined with the new assault on the body caused by the naturally occurring arrest would justify the decision that more harm than good would be done by an attempted resuscitation. The operating room physician, however, may argue that an anesthesia-induced arrest is a different matter, one that the patient did not envision when issuing the non-resuscitation instruction. Moreover, physicians may feel it is unfair to them to let a course continue that will leave them the immediate and active cause of the patient's death. They may claim that they have a moral or legal right to attempt to reverse an anesthesia accident that they actively (though unintentionally) caused.

On the other hand, the patient's refusal of CPR would appear to be a valid refusal to consent to treatment. It is possible that the patient intended that it extend to the operating room. Such patients, normally already terminally ill, may realize that any cardiac arrest, whether man-made or 
naturally occurring, would add complexity to an already bleak prognosis.

This problem might be addressed by clarifying the precise nature of the patient's instruction refusing CPR. If both parties agree to exclude operating room arrests from the refusal of CPR, the problem is resolved. But what should happen if the patient is willing to accept palliative surgery, but only if CPR will not be attempted in the event of an arrest and the surgeon is unwilling to do the surgery on those terms?

EMT and Other Non-Physician Interventions. Another case that tests the limit of the consensus in favor of honoring a competent patient's right to refuse medical treatment arises when the patient suffers a crisis outside the normal medical setting. The Kennedy Institute of Ethics Journal published the tragic story of a 16-year-old who, with the full support of her parents and medical staff, had refused a heart transplant (Kuehl, Shapiro, and Sivasubramanian 1992). There was real doubt about its effectiveness and, after careful deliberation, all parties had come to an understanding that the transplant would not be attempted.

The young woman also had a valid instruction not to attempt resuscitation in the event of a cardiac arrest. The medical staff and her parents concurred in this decision as well. Their problem was what should happen were her cardiac arrest to occur outside the hospital - at her school or on the street. Teachers or other onlookers would plausibly call emergency medical technicians who would most likely attempt resuscitation.

It seems wise that as a general rule emergency personnel who encounter a patient in crisis should resuscitate first and then assess a nonresuscitation instruction from the patient or family. It would be virtually impossible during the crisis to assess the legitimacy of such instructions, whether they are the most recent position, and whether the family member is the valid surrogate. On the other hand, patients who have carefully worked out a decision against resuscitation should not be subjected to needless, burdensome resuscitation efforts.

Part of the problem could be addressed by creating a legally binding protocol allowing such patients to register with emergency rescue services in advance so that the validity of their non-treatment instructions would be known.

The State of Virginia has recently passed a law authorizing EMTs to avoid resuscitation attempts for people with valid non-resuscitation instructions (Virginia Acts of Assembly 1992, Chapter 412, sec. 54.12987.1). That authorization, however, is limited to written orders by physicians in a form approved by the Board of Health. In addition, with 
so many people trained in CPR, it might not be the local rescue squad that attempts the resuscitation. As yet, aside from this new law in Virginia, we have no consensus on whether treatment refusals by competent patients are legally binding on rescue personnel, teachers, and others who are believed to have a duty to rescue.

\section{Damages for Treatment without Consent}

Still another place at which the consensus is stretched to its limits is the question of moral and legal liability for treating patients without or against their consent. Cases have arisen, but no clear pattern has emerged (see e.g., Estate of Leach v. Shapiro, 469 N.E.2d 1047 (Ohio App. 1984)). If competent patients have a valid moral and legal right to refuse medical treatment, it stands to reason that they should have some recourse if they are treated against their consent. Real harms are incurred. Patients suffer physical pain; they may suffer mentally realizing that their prolonged decline toward a slow painful death must continue. Hospital bills will still have to be paid. I have suggested that health insurers have a moral duty to insist that treatments be reimbursed only when there is reason to believe that the patient (or patient surrogate) had consented to treatment or, in the case of an emergency, would have consented to it (Veatch 1988, p. 35 ). Someday the consensus on forgoing treatment will have to include a consensus on whether damages - compensatory and punitive-must be paid when treatment is rendered without the consent of the patient.

\section{Third-Party Interests}

The consensus supporting the right of competent patients to forgo lifesustaining treatment has always contained a series of exceptions. One of these is the existence of significant third-party interests. In the early years this provided justification for forcing blood transfusions on adult Jehovah's Witnesses with dependent children who would be abandoned by the death of the parent were the blood not provided (In re President \& Dirs. of Georgetown College, 331 F.2d 1000 (D.C. Cir.), aff'd, 331 F.2d 1010 (D.C. Cir.), cert. denied sub nom., Jones $v$. President and Directors of Georgetown College, Inc., 377 U.S. 978 (1964); Powell v. Columbian [sic] Presbyterian Medical Center, 267. N.Y.S.2d 450 (Sup. Ct. 1965)). This reasoning even has been applied to pregnant women to authorize blood transfusions (Raleigh Fitkin-Paul Morgan Memorial Hospital v. Anderson, 201 A.2d 537 (N.J.), cert. denied, 337 U.S. 985 (1964)), to order Cesarean sections (Jefferson v. Griffin Spalding County Hospital 
Authority, 274 S.E.2d 47 (Ga. 1981); In re Madyun Fetus, D.C. Superior Court, Civil Division (No. 189-86, 25 June 1986)), and to defend new fetal surgery procedures (see Kolder, Gallagher, and Parsons 1987) as well as to support traditional forced treatment for infectious diseases.

The idea that third-party interests justify overriding patient autonomy is a controversial one. Taken to an extreme, it could justify not only denying access to medical care in order to save society money, but also forced participation in dangerous medical research against the wishes of the subject.

Traditional philosophical defenders of liberty have acknowledged the “harm-to-others" principle (Mill [1859] 1956, pp. 91-92; Feinberg 1986, pp. 52-57). Nevertheless, I am increasingly convinced that the harm-toothers justification of overriding autonomy in medical decisions needs more work. While there is a vague awareness that some third-party interests are relevant, there is also an awareness that there is great danger in straight utilitarian reasoning that would permit treatment (or nontreatment) of any patient based solely on the aggregate social consequences.

Consider, for example, the homeless derelict who was found on the street in a major East Coast city with frostbite that had led to a gangrenous foot that physicians recommended should be amputated (for a similar case see Kessler (1984)). The patient, arguably legally competent, refused saying he wanted to go out with both feet. The problem was not with the refusal itself; all recognized that if he were competent he had a right to refuse. The problem was that as a Medicaid patient he would be entitled to very expensive and prolonged care made necessary by the refusal of the amputation. Even then the physician felt that he would probably not survive. Could third-party interests in preserving the state's Medicaid funds justify compulsory amputation in such a case? It is here that the idea that thirdparty interests justify forced treatment breaks down.

One might reject any straight utilitarian justification for overriding a legally competent patient's refusal while accepting other, more limited, moral grounds of justification. The principle of fidelity might generate an obligation on the part of parents and others with guardian responsibilities to receive certain medical treatments against their will. This might explain the special duty of some Jehovah's Witness parents to get blood transfusions when it is in the interests of their children. By contrast, if hypothetically there were an unrelated child who would benefit equally from the forced transfusion of the adult, the fidelity principle would not justify the coercion. 
The principle of justice may also provide a limited basis for forcing treatment against a competent patient's consent. Consider, for example, a principle of justice that holds that social practices are morally right to the extent that they benefit the least well-off. For example, if a military physician suffered a non-life-threatening battlefield injury that could be treated rather easily and his or her immediate treatment were necessary to serve the needs of more seriously injured (that is, worse off) casualties, forced treatment of the physician might be defended in the name of the principle of justice. This appeal to justice would permit limited coerced treatment for the benefit of the least well off in society, but in a way that could not be extended to general economic or social benefits the way the principle of utility would. This appeal to justice as a basis for overriding autonomy will have even wider application as a grounds for limited restriction on access to treatment, but in special cases it can also provide a basis for overriding treatment refusal.

I believe some such third-party interests will eventually be seen as legitimate, while others will not.

\section{The Ethical Integrity of the Medical Profession}

Meisel has pointed out that court cases since the 1970s have recognized that in theory the ethical integrity of the medical profession is another societal interest that might override a competent patient's right of refusal. I am increasingly uncomfortable that this throw-away line has survived in the literature on forgoing life-sustaining treatment.

Historically, when treatment has been forced against a competent patient's wishes several arguments have been offered in defense of the decision. For example, five reasons for forcing a blood transfusion on an adult patient were noted in a Georgetown University Hospital case. Some of them were surely valid. For example, she might have been incompetent. She was the parent of a small child to whom she might have had a fidelity duty to receive the transfusion. Another argument mentioned was the integrity of the medical professional: the physician would have been offended had he been forced to stand by and let his patient die.

But it is not clear that appeal to the ethical integrity of the medical profession adds any weight to refusals that are already justified on other grounds. The issue is whether the ethical integrity of the medical profession by itself ever would justify overriding a competent patient's refusal or that it would provide any basis for contemplating overriding a patient for whom there were no other basis for doing so. 
Although it continues to be cited as a basis for overriding, I am not aware of any legal case in which that reason alone led to overriding, nor of any case in which it could justify overriding the patient's refusal.

\section{Borderline Competence}

There is one final group of cases involving patients never determined to be incompetent about which consensus appears to be lacking. Some patients are categorically legally incompetent: children, the severely retarded, and those adjudicated incompetent by a court. Other adults are presumed competent. Yet some patients not categorically incompetent and never adjudicated to be incompetent lack the mental capacity to make their own life-sustaining treatment decisions. While there is a general consensus that some such patients exist and that it would be irrational to honor their refusals of life-prolonging treatment, there is no consensus on exactly how such cases should be handled.

Some advocate a clear distinction between competency, which they take to be a legal term, and capacity, which they take to refer to the mental state of the individual whether competent or incompetent (Hastings Center 1987, pp. 131-33; Buchanan and Brock 1989, pp. 17-29). While the distinction is surely a valid one, the consensus is in trouble when it comes to deciding what should be done in cases in which patients who are not formally incompetent nevertheless lack capacity and, vice versa, when those who are legally incompetent actually possess adequate capacity to make medical decisions.

Some argue that if those who have not been adjudicated incompetent but lack capacity have their refusals honored, terrible harm could befall them. They press for informal, clinical assessments with referral to ethics committees and other internal hospital review mechanisms.

On the other hand, no one at the clinical level-no physician, no psychologist, no family member-has the legal authority to declare such patients incompetent and remove decision-making authority from them. If any of these private citizens is given the authority to override an adult patient's refusal when that adult has not been declared incompetent, there is a serious risk that the patient's autonomy will actually be violated.

I believe that most such cases can be resolved by a combination of mechanisms including clinical counseling and ethics committee discussion with the permission of the patient. But the only way to protect the patient who insists on refusing treatment and avoid unilateral, private declarations of lack of capacity is to insist on formal judicial review to declare incom- 
petency before overruling the patient. I believe that in almost all such refusals court review can be obtained in a sufficiently timely manner that the patient's interests will not be jeopardized. This leads me to insist that an adult patient's refusal of treatment should be overturned only with formal judicial due process. Clearly, others more paternalistically inclined worry more about the risks of getting a formal review and less about the risks of violating the rights of patients who actually turn out to be competent. The consensus has once again reached its limits.

There is a special variant about which we as a society have even less clarity. While I hold that most adults who have never been adjudicated incompetent and who are refusing life-sustaining treatments can have their questionable refusals reviewed judicially without risking injury, I admit there is a small, special group of exceptional cases.

David Jackson and Stuart Youngner (1979) published a series of six treatment refusal cases in which they claim patients would be injured if their refusals were honored. Five of them seem clearly to me to be cases in which judicial review would not have created a problem.

The sixth case, however, has truly troublesome overtones. A young woman with a history of chronic asthma was admitted to the hospital suffering from pneumonia. She refused continued treatment for irrational reasons. Although she had never been adjudicated to be incompetent and should therefore be presumed competent, the clinicians had good reason to believe that she was not making a substantially autonomous choice. Still, they did not have the legal authority to declare her incompetent and arguably taking the time to get even a telephone authorization to treat against the patient's expressed wishes would have led to serious permanent injury, perhaps even death.

Intuition tells us that somehow the clinician has to be authorized to treat in such cases, but how can such a policy be institutionalized without giving clinicians blanket authority to declare patients incompetent without due process and thereby subjecting many competent patients to treatment against their competently expressed wishes? If one believes that violating autonomy is truly a serious offense, then social practices involving the declaration of incompetence should maximize protection against unwarranted declarations.

I believe that in such cases the clinician should make a reasonable effort to inform the patient and a surrogate, if one is available, of the clinician's belief that the patient lacks capacity to make substantially autonomous decisions. If the patient and surrogate do not object, then the decision- 
making authority can safely transfer to the surrogate. I do not know any legal basis for this private transfer of decision making, but it seems to me to be a prudent and safe course.

If, however, the patient or surrogate objects, I would normally want to presume competency (and therefore presume decision-making capacity) until a formal judicial review determines otherwise.

That leaves us with the truly unresolvable case in which seeking the review would do serious irreparable harm. I would like to see a law authorizing a very limited right of one private citizen to declare another citizen "incompetent." Such a law would place the burden of proof on the one making the private declaration. If, retrospectively, the declaration of incompetency cannot be sustained, the one intervening against consent would be guilty of an assault and subject to its penalties. This is one possible solution, but clearly no consensus has yet emerged about how to deal with these difficult cases of borderline competency.

\section{INCOMPETENT PATIENTS}

This brings us to the more problematic group of incompetent patients. Here we will find additional limits to the consensus at several points where unusual combinations of circumstances force us to go beyond established decision-making strategies.

There is general agreement that in the case of incompetent patients a lay surrogate ought to have the authority to decide about life-sustaining treatments. In the real world of clinical medicine these lay surrogates may be dominated by attending physicians or damned with faint authority expressed in the language of giving the surrogate a voice. Talk of clinicians giving the family member a "voice" in "shared" decision-making, seems to presume that the clinician has some legitimate role and that the surrogate merely is one of the relevant, legitimate decision-makers.

By contrast, increasingly the consensus supports definitive authority for the surrogate. Unless a guardian has been appointed by the court or a surrogate has been named by the patient through a durable power of attorney, the next of kin is generally recognized as the appropriate surrogate. Laws in 13 states and the District of Columbia specify that the next of kin assumes that role (Society for the Right to Die 1991). The surrogate's role is, first, to see that the patient's actual choice, if known, is followed, next to make a substituted judgment based on what it is believed the patient would have wanted to the extent that can be known, and finally, to pursue what is believed to be in the patient's best interest 
if an actual or substituted judgment is not definitive. There are several problems with this presumption of next-of-kin surrogacy, however.

\section{The Surrogateless Incompetent}

The most vivid is the tragic case in which a patient is incompetent to express his wishes and there is no next of kin or other candidate available to be the surrogate. This group, fortunately, rather small, is alone, dying, and out of control. Nevertheless, reason tells us that for some such patients, some life-prolonging treatment will be considered that is so painful, burdensome, or implausible that, on balance, it would fail the proportionality test; it would not offer more benefit than harm. If we really comprehend the enormous number of possible but implausible interventions and realize that virtually no patient who is able to communicate wants all of them, it seems only reasonable that some life-sustaining intervention at some point will also be inappropriate for the surrogateless incompetent patient.

The problem is who should make the momentous determination that these patients who cannot speak for themselves would literally be better off dead. Sometimes attending physicians have assumed this decisionmaking role. Although North Carolina and Oregon specifically authorize physicians to make decisions for those without surrogates (Society for the Right to Die 1991, pp. NC-4, OR-4), in general there is no legal basis for assuming they have this authority, and there are good reasons to oppose that approach. Such decisions are fundamentally moral, not technical. If a physician makes the choice it will necessarily reflect personally held religious and philosophical values, and there is no reason why this vulnerable patient should be subjected to the personal values of a randomly assigned care giver. Since clinicians' values are distributed over a broad range like the rest of the population's, a random decision based on the clinician's personal values exposes patients to some physicians who are all too facile about letting patients die while others become victims of ultra-conservative values that elevate biological life to the ultimate good.

The use of ethics committees at the local hospital only partially corrects for this random variation. Hospitals are social institutions that themselves reflect the value profile of their sponsors, which will also vary over a spectrum of values, with some sponsors institutionalizing an ultra-liberal willingness to let terminally ill patients die and others an ultra-conservative insistence on preserving all life. In addition, committees are made up disproportionally of physicians and other health professionals, and there is good evidence that the values of these groups as groups do not randomly 
reflect those of the general population. Consequently, even if an ethics committee neutralized the individual biases of attending physicians and controlled for the institutional biases of sponsors, the value commitments of the professions serving on the committee would still distort its judgments.

There is another reason why clinicians should not be responsible for making decisions to forgo life-sustaining treatments for their surrogateless incompetent patients. The clinician at the bedside is the one person who will almost certainly be present to see the choice made by the decisionmaker thereby serving as the patient's last line of defense against irresponsible surrogate decisions. If the clinician becomes the surrogate, that line of defense will be lost.

In the end, we must either legislate to give the physician in charge de facto surrogacy for the patient for purposes of forgoing life-sustaining treatment or develop some other policy. For this narrow group of vulnerable patients, a good case can be made that a formal judicial review should be provided to maximally protect them against abuse.

\section{Competing Bonded Surrogates}

In some cases, a similar problem arises even when family members or friends of the patient are available for the surrogacy role. I refer to all potential surrogates who have known the patient and have a social bond with him or her as "bonded surrogates." If the patient is incompetent and has not designated a surrogate while competent, it is not always obvious who the bonded surrogate ought to be.

Conflict Among Family. There are cases in which families disagree over what should be done for a loved one. A more distant relative may disagree with the next of kin. That less closely related individual may actually know the patient better or have served in a de facto guardian capacity taking care of the patient during a long illness. What should happen in such disputes? Once again we have pushed the consensus to its limits.

It is common for policy commentators to acknowledge that sometimes the next of kin should not be the surrogate. Some advocate that the physician should assess the roles of various family members and designate the one to serve as the surrogate (Hastings Center 1987, p. 24).

This approach poses real problems, however. The physician may not be in a good position to make the choice. The family member who favors a course supported by the physician is likely to be designated. Moreover, whoever is chosen by the clinician will be the recipient of the wrath of 
the ones not chosen, hardly making for a good family support system for a difficult time to come.

My inclination is to support a hard and fast rule that whenever a patient is incompetent and has not designated a surrogate, the next of kin will be the patient's agent until that next of kin yields to someone else or is replaced by a court. In some cases - for example an elderly, infirm spouse-the next of kin may readily give the actual authority to some other party. It makes no practical difference whether the other party is officially designated surrogate or merely transmits a decision to the next of kin who, in turn, conveys it to the physician.

For cases in which a dispute persists, the other potential bonded surrogates should have the authority to ask for an ethics committee review and judicial intervention, if necessary. The alternative by which the physician picks from the available pool of candidates would eventually lead to the same result. A distant relative picked by the physician could be challenged by the next of kin or another potential "bonded" surrogate, who would then be the one asking for ethics committee or judicial review. I believe a rigid presumption of next-of-kin surrogacy with the right of others to ask for review is the cleanest social policy. Whatever policy is favored, it is clear that no consensus yet exists.

Non-family Bonded Surrogates. The same problem arises for cases in which a close friend (or lover) appears to be the most appropriate bonded surrogate. The best solution is to make sure the patient designates an agent while competent. However, if that is not done, problems can arise if the physician, or anyone other than a judge, assumes the authority to replace the legal next of kin with someone who seems better. I prefer, even in the obvious case of the AIDS patient with a homosexual lover, to begin with the legal presumption of next-of-kin surrogacy. Sometimes parents will yield to the obvious close bond of the patient's partner. In other cases formal review may be necessary if the patient has not designated the partner as a surrogate. For the clinician to rely on the partner's claim that he can speak for the patient seems risky and destined to lead to unpleasant controversy.

\section{Surrogates Abandoning Literal Best Interest}

Perhaps the most important cases at the fringe of the consensus involve surrogate decisions in which the surrogate makes an unexpected choice. It is now established that the surrogate must first attempt a substituted judgment and, if adequate information is not available, strive to do what 
is in the patient's best interest. Sometimes, however, the surrogate may come up with what appears to outsiders to be less than the best choice.

Although it is now common rhetoric to insist that the surrogate must pursue the "best interest" of the patient, there are a number of reasons why the best interest standard is unacceptable and will eventually be replaced. Holding to the best interest standard would require that surrogates choose literally the best course even if they favored another course deemed almost as good by outsiders. This could arise because the family's cultural, religious, and philosophical values lead them to somewhat atypical views about what is best for the patient.

Replacing Best Interest with a Reasonableness Standard. Previously, I suggested that in such situations society does not insist on the literal best, but only on "the standard of reasonableness" (Veatch 1984, pp. 440-49, 465). Then I held that bonded surrogates should strive to do what they think is best and that their judgment must be tolerably within reason, but it need not be the literal best choice. I believed that if we insisted on the literal best choice, we would be tied up in endless, counterproductive litigation trying to determine what was best and we would infringe on the limited autonomy necessary for families to function well (President's Commission 1983, pp. 215-23; In the matter of Phillip Becker, 92 Cal. App. 3d 796, 156 Cal Rptr. 48 (1979), cert. denied sub nom. Botbman $v$. Warren B., 445 U.S. 949 (1980); In re L.H.R., 321 S.E.2d. 716 (Ga. 1984)). As of now the consensus expressed in the common rhetoric does not acknowledge the need for tolerance in surrogate decisions for modest deviations from what is best for the patient.

Parental Conflict of Best Interest Duties. Now I am not sure that even in theory the surrogate should always strive for what he or she believes is best for the patient. An even less well-recognized problem is emerging having to do with the necessity for deviating from the best interest standard. It arises most prominently in cases of parental decision making for critically ill infants. The consensus begins with the premise that parents acting as surrogate decision makers for their children must do what is best. We have seen that there might be room for limited parental discretion based on differences in interpretation of what is best. But there is a more significant problem. If the critically ill youngster has a sibling and the parents also have a moral and legal duty to do what is best for the sibling, they are placed in an impossible position whenever what is best for the critically ill child conflicts with what is best for the sibling. This can involve trivial 
conflicts. The critically ill child would be best served if parents were constantly present at the hospital, but the sibling would be best served if at least one parent were away some of the time. At a more serious level, the critically ill child might be best served if the entire family estate were spent on treatment or if a commitment were made to bring the seriously handicapped child home for long-term home care. Either of these may not be what is best for a sibling. The parents cannot literally do what is best for both simultaneously.

I believe eventually the standard of reasonableness will emerge to replace the best interest standard. Under it, parents would be expected to do what is reasonably in the child's interest taking into account all the other moral obligations the parents have as well as their personally held interpretation of what is best. Often this will not require, or even permit, doing what is literally best for the sick child. However, our social consensus does not yet incorporate such a qualifier on the best interest standard.

Societal Conflict with The Patient's Best Interest. Just as parents have a duty to siblings that may require limits on serving the patient's best interest, so society has conflicting obligations that may limit its ability to provide a level of insurance coverage that will permit serving the incompetent patient's best interest. It can be shown that it is irrational for a social insurance scheme to fund care up to the point that is literally best for the patient (Veatch 1986, 1991).

This means that morality will sometimes require that society not permit the incompetent patient's best interests to be served. It would violate the principle of justice if it were. However, the rhetoric of our legal and public policy discussion does not yet reflect this reality. While no consensus exists on exactly how these social limits grounded in justice shall be established, some such limits surely must exist.

\section{Care of "New Persons"}

Although there is now wide-spread agreement that advance directives from formerly competent patients should be followed to the extent that their implications can be discerned, there is one newly emerging kind of case in which this is in real doubt. When competent patients write advance directives they envision a time when they will exist as persons who are incapable of conveying their precise, well-thought-out desires about terminal care. They presume, however, that the values they presently hold ought to be used for the later care decisions.

We know that some patients, such as advanced Alzheimer's patients, 
lapse into an incompetency in which there appears to be little or no continuity with their former selves. They appear to have no memory of their former life and are even unable to recognize friends and family. It is as if they were new persons, perhaps with new sets of desires and values.

Some who are generally defenders of the legitimacy of advance directives hold that if a "new person" now exists the morally correct course is to do what would serve this new person's interest rather than what was fitting for the old person (Buchanan and Brock 1989, pp. 184-89; Dresser and Robertson 1989). They reason that the old person will never know that his wishes were violated and the new person, by definition, will be better off than if the now obsolete judgments were used to make life-and-death decisions.

On the other hand, many people who envision a world in which their advance directives were overturned in favor of what now appears to fit the new interests of this new person are offended. They face a future life in which they would continually have to worry that their wishes would not be followed. Their position is analogous to that of one who has written an idiosyncratic economic will in a society that has an announced policy of overturning wills that appear not to be reasonable. The only difference is that in the case of an advanced Alzheimer's patient one can argue that there is a "new person" who has a new set of interests while in the case of an economic will there is no new person, only other members of the society who would stand to benefit by overturning the will.

Considered moral judgments about whether to honor or overturn an advance directive that appears to conflict with the best interest of the "new person" vary widely. Surely, there is no new consensus; the old consensus would commit us to a position of ignoring the best interests of an incompetent "new person" who is only tenuously connected with the one who wrote the advance directive. This appears to violate the apparent consensus that we should serve the "best" or "reasonable" interests of incompetent persons whose wishes while competent are unknowable. On the other hand, overturning the advance directive would violate even more blatantly the consensus giving priority to advance directives.

\section{CONCLUSION}

There is no denying that a substantial moral and legal consensus exists about how to handle most cases involving forgoing of life-sustaining treatment. The core elements seem firmly established. Yet as we apply that consensus to more and more cases we discover novel situations to which 
the consensus cannot be applied directly. Unlike the controversy over active mercy killing, it is not necessarily that there is enormous moral or legal disagreement about these cases. Rather we are discovering new twists on the old problems for which our old principles-proportionality, autonomy, substituted judgment, and best interest-do not provide clear conclusions. We are ready for a new generation of moral debates in the ethics of terminal care from which newer, more subtle guidelines will have to emerge.

\section{REFERENCES}

Buchanan, Allen E., and Brock, Dan W. 1989. Deciding for Others: The Ethics of Surrogate Decision Making. Cambridge: Cambridge University Press.

Dresser, Rebecca S., and Robertson, John A. 1989. Quality of Life and NonTreatment Decisions for Incompetent Patients: A Critique of the Orthodox Approach. Law, Medicine, o Health Care 17: 234-44.

Feinberg, Joel. 1986. Harm to Self: The Moral Limits of the Criminal Law, vol. 3. New York: Oxford University Press.

Hastings Center. 1987. Guidelines on the Termination of Life-Sustaining Treatment and the Care of the Dying. Briarcliff Manor, NY.

Jackson, David, and Youngner, Stuart. 1979. Patient Autonomy and 'Death with Dignity.' New England Journal of Medicine 301: 404-408.

Kessler, Ronald. 1984. Patient Sues to Block Amputation of Leg. The Washington Post (June 2): B3

Kolder, Veronica E. B.; Gallagher, Janet; and Parsons, Michael T. 1987. CourtOrdered Obstetrical Interventions. New England Journal of Medicine 316: 1192-96.

Kuehl, Karin S.; Shapiro, Steven; and Sivasubramanian, K. N. 1992. Should a School Honor a Student's DNR Order? Case History of S.A. Kennedy Institute of Ethics Journal 2: 1-3.

Lynn, Joanne, and Childress, James F. 1983. Must Patients Always be Given Food and Water? Hastings Center Report 13 (5): 17-21.

Meilaender, Gilbert. 1984. On Removing Food and Water: Against the Stream. Hastings Center Report 14 (6): 11-13.

Meisel, Alan. 1992. The Legal Consensus About Forgoing Life-Sustaining Treatment: Its Status and Its Prospects. Kennedy Institute of Ethics Journal 2: $309-45$.

Mill, John Stuart. [1859] 1956. On Liberty. Ed. C. V. Shields. New York: The Liberal Arts Press.

President's Commission for the Study of Ethical Problems in Medicine and Biomedical and Behavioral Research. 1983. Deciding to Forego Life-Sustaining 
Treatment: Ethical, Medical, and Legal Issues in Treatment Decisions. Washington, DC: U.S. Government Printing Office.

Society for the Right to Die. 1991. Refusal of Treatment Legislation: A State by State Compilation of Enacted and Model Statutes. New York: Society for the Right to Die.

Veatch, Robert M. 1984. Limits of Guardian Treatment Refusal: A Reasonableness Standard. American Journal of Law and Medicine 9: 427-68.

1986. DRGs and the Ethical Reallocation of Resources. Hastings Center Report 16 (3): 32-40.

1988. Justice and the Economics of Terminal Illness. Hastings Center Report 18 (4): 34-40.

1991. Allocating Health Resources Ethically: New Roles for Administrators and Clinicians. Frontiers of Health Services Management 8 (1): 329. 